J. Clin. Chem. Clin. Biochem.

Vol. 27, 1989, pp. $791-796$

C) 1989 Walter de Gruyter \& Co.

Berlin - New York

\title{
Some Aspects of the Chromogen 3,3',5,5'-Tetramethylbenzidine as Hydrogen Donor in a Horseradish Peroxidase Assay
}

\author{
By R.W. Bally and T. C. J. Gribnau \\ Scientific Development Group Organon Int. B.V. Oss, The Netherlands
}

(Received October 28, 1988/June 21, 1989)

\begin{abstract}
Summary: Enzyme immunoassays frequently incorporate the use of horseradish perosidase as the enzyme label. This enzyme usually catalyses the oxidation of a chromogen which can be quantified after termination of the enzyme reaction. A chromogen widely used for this purpose is $3,3^{\prime}, 5,5^{\prime}$-tetramethylbenzidine. The two electron oxidation of tetramethylbenzidine yields a component with an absorbance maximum at $450 \mathrm{~nm}$. If the enzyme reaction is terminated by lowering of the $\mathrm{pH}(<1.0)$, an additional increase of the absorbance at $450 \mathrm{~nm}$ is observed.
\end{abstract}

It is shown that this additional increase is partly due to a 1.4-fold increase in the molar lineic absorbance of oxidized tetramethylbenzidine, caused by the acidic $\mathrm{pH}$, as well as a quantitative shift of the existing equilibrium between tetramethylbenzidine, oxidized tetramethylbenzidine and their charge-transfer complex. The total absorbance increase upon acidification of the reaction mixture depends therefore on the reaction conditions as well as the reaction coordinate.

\section{Introduction}

Horseradish peroxidase ${ }^{1}$ ) is frequently used as a label in enzyme immunoassays. It catalyses the oxidation of a redox indicator by $\mathrm{H}_{2} \mathrm{O}_{2}$. A redox indicator widely used in this reaction is $3,3^{\prime}, 5,5^{\prime}$-tetramethylbenzidine, a chromogen that is easily quantified by colorimetry (1).

The reaction involves transfer of two electrons (fig. 1). In a first step, a cation radical reaction intermediate is formed (B) which is the result of one electron transfer (2).

In a second step, as a result of a second electron transfer, the cation radical is further oxidized to form the yellow coloured diimine derivative (D) of tetramethylbenzidine. Two of the intermediate cation radicals may however combine to form a blue coloured charge-transfer complex (C), which may also be considered to consist of a molecule tetramethylbenzidine

1) Enzyme:

Horseradish peroxidase, Donor: hydrogen-peroxide oxidoreductase, EC 1.11.1.7
(A) and a molecule of its diimine derivative (D); an equilibrium state, that depends on the reaction conditions, exists between these various molecules.

The amount of oxidation product(s) formed, is generally quantified by spectrophotometry. Prior to photometric detection, the turnover of tetramethylbenzidine by horseradish peroxidase $/ \mathrm{H}_{2} \mathrm{O}_{2}$ is commonly terminated by lowering the $\mathrm{pH}$ of the reaction mixture, preferably with a strong acid like $\mathrm{H}_{2} \mathrm{SO}_{4}$, to a value below unity. An additional effect of acidification, after correction for dilution, is a substantial absorbance increase at $450 \mathrm{~nm}$, the absorbance maximum of the diimine. This absorbance increase may be attributed to a number of possible effects, such as:

- a pH effect on the molar lineic absorbance of the diimine;

- a shift in the equilibrium between the chargetransfer complex and its constituents;

- auto-oxidation of the charge-transfer complex under acidic conditions;

- a combination of the above. 


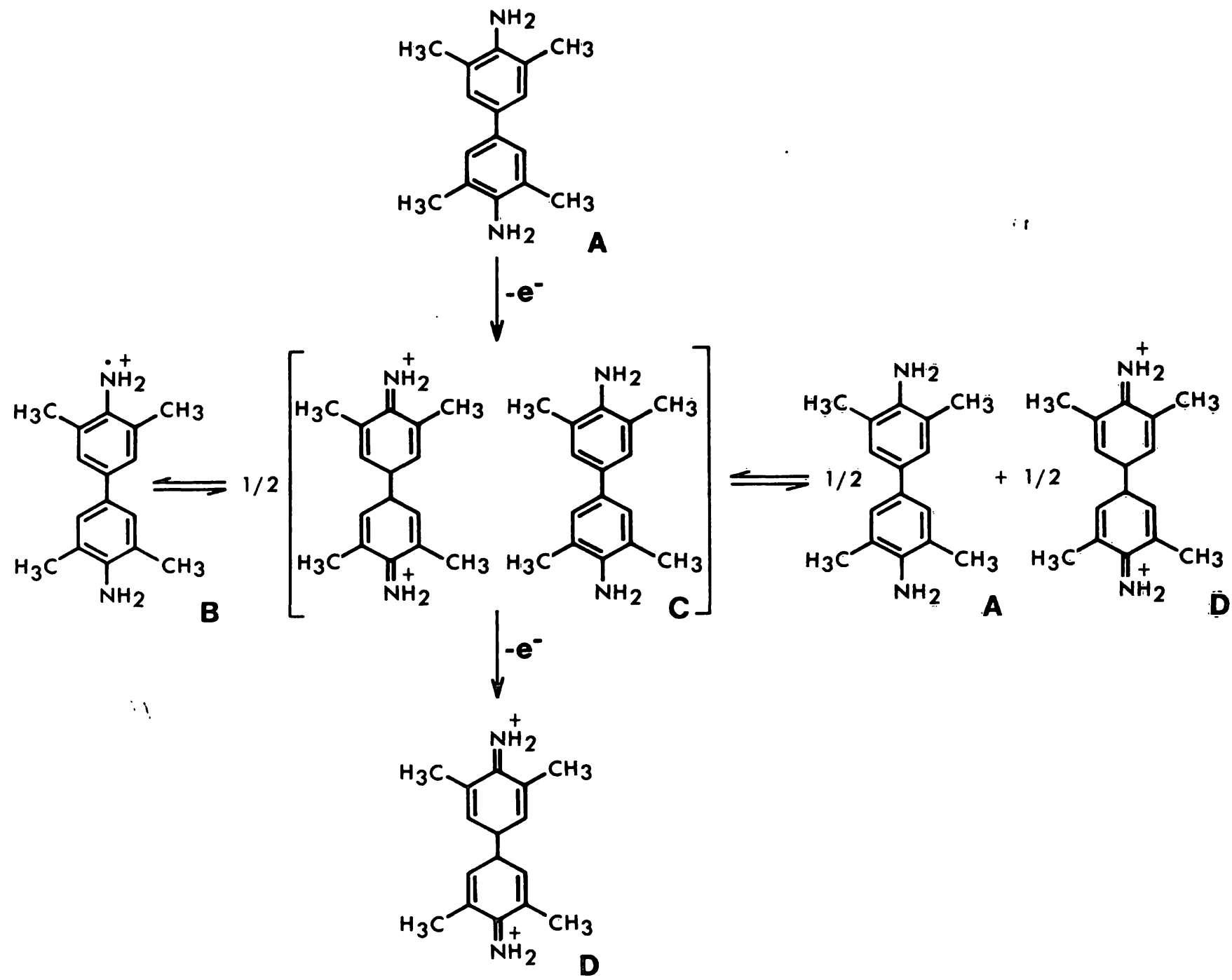

Fig. 1. Two electron oxidation of 3,3',5,5'-tetramethylbenzidine tetramethylbenzidine;

(A) - tetramethylbenzidine $\left(\lambda_{\max }=210\right.$ and 285 at $\left.\mathrm{pH}>3.0\right)$;

(B) - cation-radical;

(C) - charge-transfer complex $\left(\lambda_{\max }=380,650\right.$ at $\left.\mathrm{pH}>=1.0\right)$;

(D) - oxidized tetramethylbenzidine (diimine derivative, $\lambda_{\max }=450$ ).

The mechanism of this acid-induced absorbance increase was investigated in a series of experiments, the results of which are presented in this paper.

\section{Materials and Methods}

All reagents used were of analytical grade. Water used was of Millipore Super-Q quality. Tetramethylbenzidine (free base) was obtained from Aldrich; tetramethylbenzidine $\cdot 2 \mathrm{HCl}$ from Fluka; horseradish peroxidase (freeze dried powder, $\mathrm{RZ}=3.0$ ) from Boehringer; and $\mathrm{H}_{2} \mathrm{O}_{2}(30 \%)$ from Baker.

Stock solutions of the free base of tetramethylbenzidine were prepared in dimethylsulphoxide. Tetramethylbenzidine $\cdot 2 \mathrm{HCl}$, horseradish peroxidase and peroxide solutions were prepared in aqueous buffer. Incubation mixtures containing the free base of tetramethylbenzidine were prepared in acetate/citrate buffer $(0.1 \mathrm{~mol} / \mathrm{l}$ sodium acetate adjusted with citric acid monohydrate to $\mathrm{pH} 5.5)$, whereas the tetramethylbenzidine $\cdot 2 \mathrm{HCl}$-containing mixtures were prepared in acetate buffer $(0.01 \mathrm{~mol} / \mathrm{l}$ acetate buffer, $\mathrm{pH}$ 4.0). All experiments were performed at ambient temperature. Specific reaction conditions are presented in the legends to the figures. All reactions were terminated by the addition of $1 \mathrm{~mol} / 1 \mathrm{H}_{2} \mathrm{SO}_{4}$ in a volume ratio of $1: 1$.

UV/VIS spectra were recorded using a Philips model PU்8700 spectrophotometer. The optical pathlength used was 0.01 meter, unless stated otherwise. Blanks were recorded using incubation mixtures without tetramethylbenzidine.

\section{Results and Discussion}

\section{Effect of $\mathrm{pH}$ on the UV/VIS spectrum of a reaction mixture}

Lowering the $\mathrm{pH}$ of a reaction mixture, in which part of the initial amount of tetramethylbenzidine has been oxidized, to a value below unity, has a dramatic effect on the UV/VIS spectrum, as previously shown by 
Gallati \& Pracht (3). This is illustrated by figure 2 in which the $\mathrm{pH}$ effect is shown for a reaction mixture allowed to attain maximum absorbance at $650 \mathrm{~nm}$, prior to acidification. This corresponds to $50 \%$ turnover of the initial amount of tetramethylbenzidine. It is observed that the absorbance band centred around $450 \mathrm{~nm}$ is increased, whereas any absorbance attributed to the charge-transfer complex $\left(\lambda_{\max }=380\right.$ and $650 \mathrm{~nm}$ ) becomes negligible.

Effect of $\mathrm{pH}$ on the molar lineic absorbance of the diimine at $450 \mathrm{~nm}$

Reactions were carried out with an excess of horseradish peroxidase $(1 \mathrm{mg} / \mathrm{l}$ reaction mixture containing either 50 or $12.5 \mu \mathrm{mol} / 1$ tetramethylbenzidine as well as $\mathrm{H}_{2} \mathrm{O}_{2}$ ), ensuring a rapid and as complete as possible turnover of tetramethylbenzidine into its diimine form. The increase in absorbance at $450 \mathrm{~nm}$ was measured with time until a plateau was observed. Spectra recorded between 200 and $700 \mathrm{~nm}$, just before $(\mathrm{pH}=5.5)$ and after termination of the reaction $(\mathrm{pH}$ $=1.0$ ) are given in figure 3 . The spectrum given for $\mathrm{pH}=1.0$ is corrected for the dilution caused by addition of $\mathrm{H}_{2} \mathrm{SO}_{4}$.

From the curve at $\mathrm{pH}=5.5$ it is concluded that the amount of charge-transfer complex in the reaction mixture is indeed virtually zero, as there is no significant absorbance at $650 \mathrm{~nm}$, an absorbance maximum of the charge-transfer complex. Any changes in the spectrum due to changes in the $\mathrm{pH}$ of the solution are therefore to be attributed to the diimine. Obviously, the molar lineic absorbance of the diimine is pH-dependent; under both reaction conditions, it is increased as much as 1.4-fold in the $\mathrm{pH}$ range 5.5 to 1.0. Since there is hardly any charge-transfer complex left in these mixtures, indicating quantitative oxidation of the tetramethylbenzidine present, it is concluded from these experiments that a 1.4-fold molar lineic absorbance increase at $450 \mathrm{~nm}$ is caused by lowering the pH from 5.5 to unity. It must be noted that this conclusion does not rely on any knowledge of molar lineic absorbances, or even on the concentration of tetramethylbenzidine and its oxidation products. It does rely on the correctness of the reaction mechanism given by Josephy et al. (2).

Effect of $\mathrm{pH}$ on the UV/VIS spectrum of tetramethylbenzidine

A decreased $\mathrm{pH}$ also has a marked effect on the absorbance band of tetramethylbenzidine at $285 \mathrm{~nm}$ (fig. 4). Acidification ( $\mathrm{pH}<3.0$ ) causes the absorbance maximum to shift from 285 to $252 \mathrm{~nm}$. The

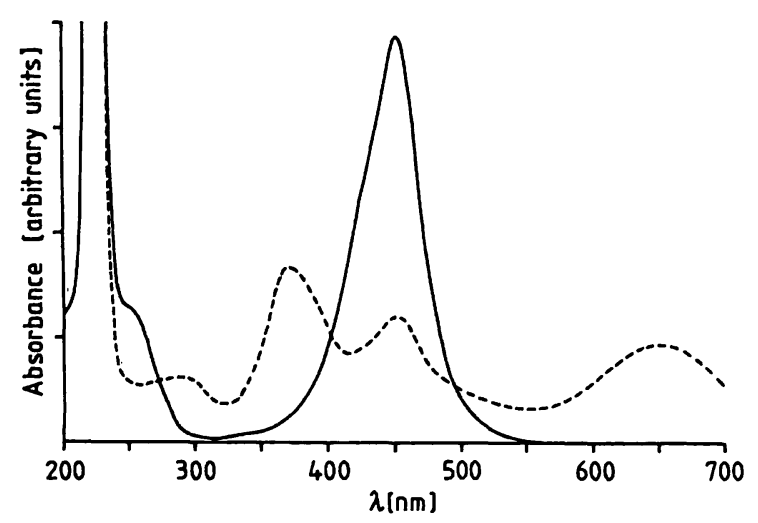

Fig. 2. UV-VIS spectrum of a mixture of tetramethylbenzidine and its oxidation products at $\mathrm{pH}=5.5(--)$ and $\mathrm{pH}$ $=1.0$ (- corrected for dilution). Conditions: $50 \%$ tetramethylbenzidine turnover, $12.5 \mu \mathrm{mol} / 1$ tetramethylbenzidine and $\mathrm{H}_{2} \mathrm{O}_{2}, 10 \mu \mathrm{g} / \mathrm{l}$ horseradish peroxidase in acetate/citrate buffer.

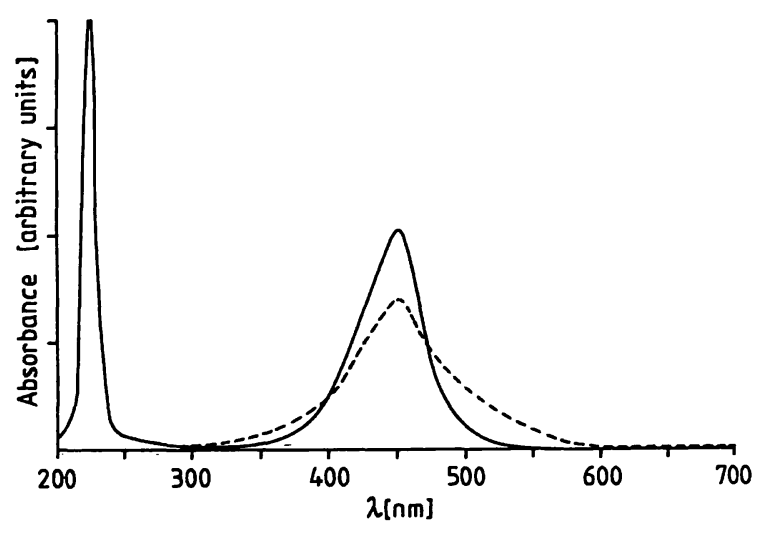

Fig. 3. Effect of $\mathrm{pH}$ on the UV-VIS spectrum of the diimine derivative of tetramethylbenzidine; spectra were recorded at $\mathrm{pH}=5.5(---)$ and $\mathrm{pH}=1.0(-$, corrected for dilution). Conditions: $12.5 \mu \mathrm{mol} / 1$ tetramethylbenzidine and $\mathrm{H}_{2} \mathrm{O}_{2}, 1 \mathrm{mg} / \mathrm{l}$ horseradish peroxidase in acetate/citrate buffer.

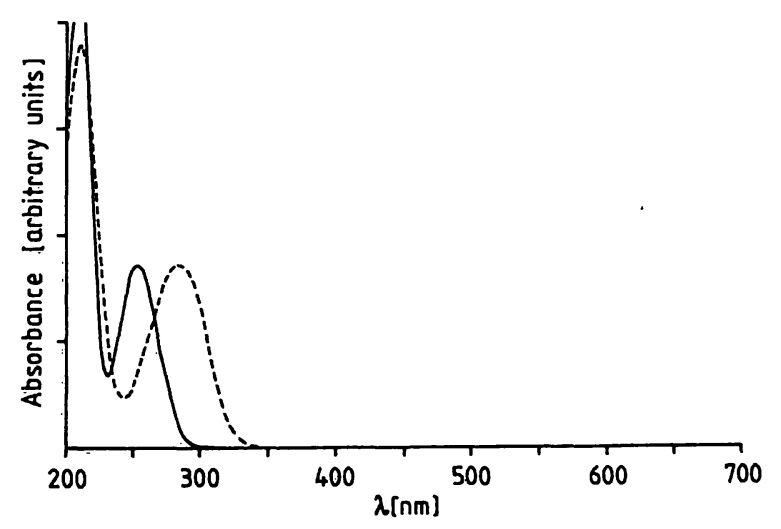

Fig. 4. Effect of pH on the UV-VIS spectrum of tetramethylbenzidine at $\mathrm{pH}=4.0(---)$ and $\mathrm{pH}=1.0$ (-, corrected for dilution). Conditions: $400 \mu \mathrm{mol} / 1$ tetramethylbenzidine in acetate buffer, optical pathlength $1.0 \mathrm{~mm}$. 
molar lineic absorbance at $285 \mathrm{~nm}$ becomes approx. 10 times smaller, whereas the molar lineic absorbances of the maxima are approximately equal.

\section{The reaction mechanism}

From the comparison of figures 2 and 3 , it is concluded that the absorbance increase at $450 \mathrm{~nm}$ upon acidification is not only dependent on the increase in the molar lineic absorbance. Acidification causes the molar lineic absorbance to increase by a factor 1.4 (fig. 3), whereas the total increase observed in figure 2 amounts to a factor 3.2. The total increase therefore clearly depends also on the reaction coordinate, being the ratio of oxidized tetramethylbenzidine over the initial tetramethylbenzidine concentration.

Full explanation of the observed absorbance increase requires a knowledge of the concentrations of all of the components involved prior to acidification, and therefore their molar lineic absorbances.

Using the reaction mechanism proposed by Josephy et al. (2), it is easily verified that the totalized amount of tetramethylbenzidine, i. e. the sum of tetramethylbenzidine (TMB) itself and its oxidation products, at any time during the reaction is given by:

$$
\left[\mathrm{TMB}_{\mathrm{t}}\right]=[\mathrm{TMB}]+2 \cdot[\mathrm{CHA}]+[\mathrm{Ox}]
$$

and therefore

$$
\left[\mathrm{TMB}_{\mathrm{t}}\right]=\frac{\mathrm{A}_{285}}{\varepsilon_{285}}+2 \cdot \frac{\mathrm{A}_{650}}{\varepsilon_{650}}+\frac{\mathrm{A}_{450}}{\varepsilon_{450}},
$$

in which

[TMB $\mathrm{T}_{\mathrm{t}}$ : the totalized concentrations of tetramethylbenzidine and its derivatives participating in the reaction;

[TMB]: the tetramethylbenzidine concentration at time $\mathrm{t}$;

[CHA]: the concentration of charge-transfer complex at time $\mathrm{t}$;

[Ox]: the diimine concentration at time $t$;

A: absorbance measurement at the indicated wavelength;

ع: molar lineic absorbance at the indicated wavelength.

Equation 2 basically contains two unknowns, i.e. the molar lineic absorbances at 450 and $650 \mathrm{~nm}$; the molar lineic absorbance of tetramethylbenzidine at $285 \mathrm{~nm}$ may be calculated from an absorbance measurement at the initial (known) concentration.
For calculation of the molar lineic absorbances, it would be sufficient to measure the absorbances at two different reaction coordinates and the same totalized amount of tetramethylbenzidine. For the sake of accuracy, however, it was decided to measure the absorbances during tetramethylbenzidine turnover by horseradish peroxidase $/ \mathrm{H}_{2} \mathrm{O}_{2}$ of a particular mixture, i. e. as a function of time. The molar lineic absorbance at 450 and $650 \mathrm{~nm}$ were subsequently calculated by means of a least-squares fit to the model given by equation 2 .

Such an approach is valid only if the absorbances at the various wavelengths can be uniquely assigned to one component, as is the case for the band maxima at 285 (tetramethylbenżidine), 450 (diimine) and 650 $\mathrm{nm}$ (charge transfer complex) but not for the absorbance band maximum at $380 \mathrm{~nm}$ (charge transfer complex). This latter band overlaps both of the adjacent bands (c. f. figs. 2, 3 and 4).

Determination of the molar lineic absorbances enables the calculation of the various concentrations that are present prior to acidification. These data are required, in order to interpret the mechanism(s) leading to the increase at $450 \mathrm{~nm}$ on acidification.

This procedure was carried out using the acetatebuffered chromogen/substrate solution with $5 \mu \mathrm{g}$ $\left(\mathrm{mix}_{1}\right)$ or $2 \mu \mathrm{g}\left(\mathrm{mix}_{2}\right)$ horseradish peroxidase per litre reaction mixture. The absorbance measurements were corrected for time differences originating from asynchronous measurement at the various wavelengths. The averaged molar lineic absorbances at $\mathrm{pH}=4: 0$ were finally found to be:

$\varepsilon_{450}=7200 \mathrm{~m}^{2} / \mathrm{mol}$ for the diimine;

$\varepsilon_{650}=4000 \mathrm{~m}^{2} / \mathrm{mol}$ for the charge-transfer complex; $\varepsilon_{285}=2006 \mathrm{~m}^{2} / \mathrm{mol}$ for tetramethylbenzidine.

The validity of the model was checked by calculating the totalized concentration of tetramethylbenzidine and derivatives, which should be the same for every measurement (see figs. $5 \mathrm{a}$ and $5 \mathrm{~b}$, Eq. 1). In these figures, the lines corresponding to the totalized amount show a slight downward trend, indicating a time effect on the measurements that is not accounted for by the model. However, the totalized amount of tetramethylbenzidine is considered to be sufficiently constant for our purposes. The molar lineic absorbances calculated for tetramethylbenzidine and the charge-transfer complex (2100 and $3900 \mathrm{~m}^{2} / \mathrm{mol}$, respectively) are in close agreement with those reported by Josephy et al. (2). The different values for the diimine (7200 and 5900) must be attributed to differences in $\mathrm{pH}$ (4.0 and 5.0, respectively). 


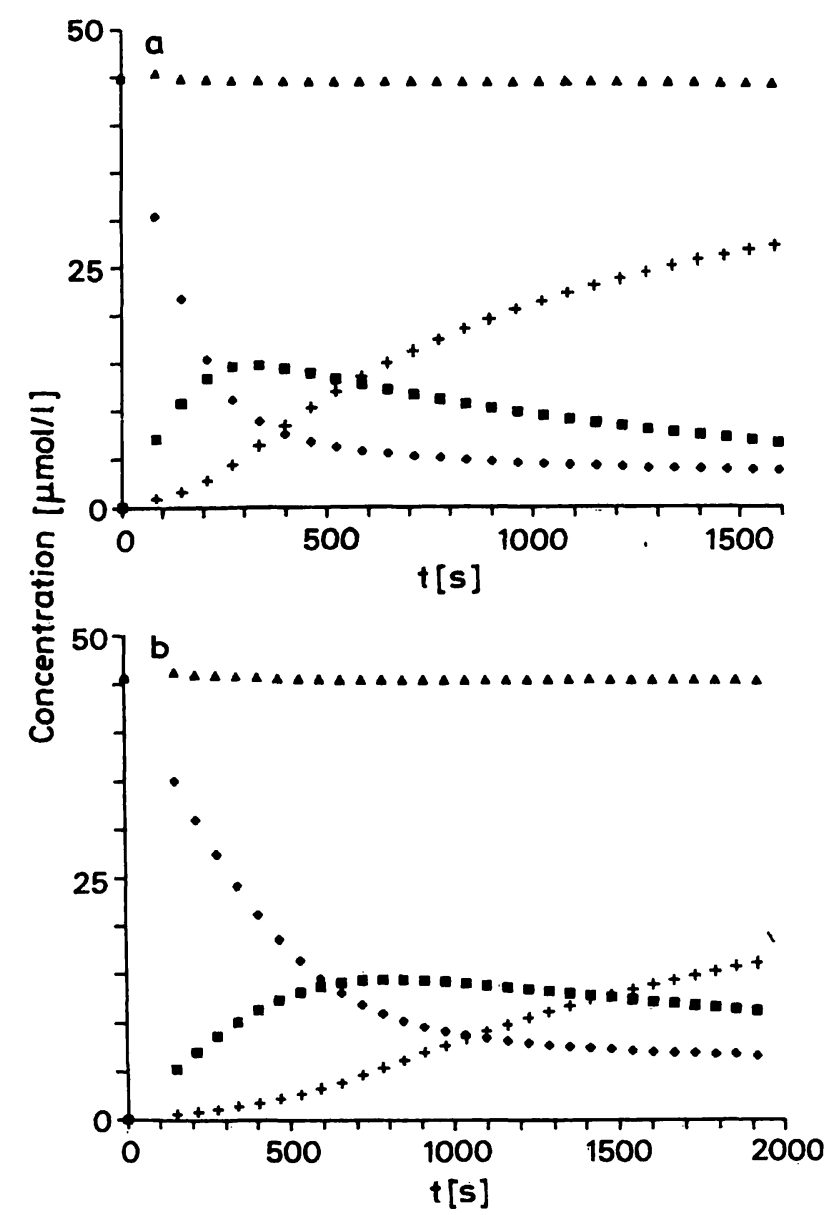

Fig. 5. Concentration (calculated) of tetramethylbenzidine $(\diamond)$, charge-transfer complex $(\boldsymbol{\omega})$, diimine $(+)$ and the totalized amount of tetramethylbenzidine $(\boldsymbol{\Lambda})$ as function of time; initial tetramethylbenzidine concentration 45 $\mu \mathrm{mol} / 1$ in acetate buffer $\mathrm{pH}=4.0$.

5.a: mixture 1; horseradish peroxidase $5 \mu \mathrm{g} / 1$ reaction mixture.

5.b: mixture 2; horseradish peroxidase $2 \mu \mathrm{g} / 1$ reaction mixture.

The absorbances at $450 \mathrm{~nm}$ prior to and after acidification are given in table 1 . The corresponding (calculated) concentrations prior to acidification are given in table 2.

The following observations can be made from the data presented in these tables.

- Prior to acidification, the absorbance ratio of mixture 1 to mixture 2 (1.54) equals the ratio of the calculated diimine $(\mathrm{Ox})$ concentrations (1.54) in both mixtures; this is to be expected if the molar lineic absorbances used are correct.

- The absorbance ratio of mixture 1 prior to and after acidification (1.33) is different from the corresponding ratio of mixture 2 (1.78). This is (again) an indication of the fact that the absorbance increase is not solely dependent on the $\mathrm{pH}$ effect on the molar lineic absorbance, but also on the reaction coordinate and therefore the initial amount of tetramethylbenzidine;
Tab. 1. Absorbance (ratios) at $450 \mathrm{~nm}$ prior to and after acidification for the mixtures containing $5\left(\right.$ mix $\left._{1}\right)$ and 2 $\left(\right.$ mix $\left._{2}\right) \mu g$ horseradish peroxidase per litre reaction mixture.

\begin{tabular}{llll}
\hline Absorbance & No acid & Acid $\left.^{2}\right)$ & Acid/no acid \\
\hline $\operatorname{mix}_{1}$ & 2.00 & 2.66 & 1.33 \\
$\operatorname{mix}_{2}$ & 1.30 & 2.32 & 1.78 \\
$\operatorname{mix}_{1} /$ mix $_{2}$ & 1.54 & 1.15 & \\
\hline
\end{tabular}

a) corrected for dilution.

Tab. 2. Various (calculated/totalized) concentrations ( $\mu \mathrm{mol} / \mathrm{l})$ of tetramethylbenzidine and oxidation products in reaction mixtures 1 and 2 just prior to termination of the reaction.

\begin{tabular}{llccc}
\hline $\begin{array}{l}\text { Concen- } \\
\text { tration }\end{array}$ & $\begin{array}{l}\text { Tetra- } \\
\text { methyl- } \\
\text { benzidine }\end{array}$ & $\begin{array}{l}\text { Charge } \\
\text { transfer } \\
\text { complex }\end{array}$ & Diimine & $\begin{array}{l}\text { Diimine } \\
+ \text { charge } \\
\text { transfer } \\
\text { complex }\end{array}$ \\
\hline mix $_{1}$ & 4.3 & 6.5 & 27.9 & 34.3 \\
mix $_{2}$ & 5.6 & 11.0 & 18.1 & 29.1 \\
mix $_{1} /$ mix $_{2}$ & & & 1.54 & 1.18 \\
\hline
\end{tabular}

- After acidification, the absorbance ratio of mixture 1 over mixture $2(1.15)$ is in close agreement with the ratio calculated for the totalized amount of diimine plus charge-transfer complex (Ox $+\mathrm{CHA}=1.18$ ).

These findings and the fact that the absorbance due to charge-transfer complex completely disappears upon acidification, lead to the conclusion that the most probable explanation for the observed absorbance increase is the complete dissociation of the charge-transfer complex, combined with a simultaneous increase in the molar lineic absorbance of the diimine, caused by the change of $\mathrm{pH}$.

The molar lineic absorbance of the diimine after acidification $(\mathrm{pH}<1.0)$ was found to be approx. 7900 $\mathrm{m}^{2} / \mathrm{mol}$ which is 1.3 times larger than the value reported by Josephy et al. at $\mathrm{pH}=5.0$. The molar lineic absorbance increases by about 1.1 when the $\mathrm{pH}$ is decreased from 4.0 to (less than) unity.

\section{Conclusions}

Acidification, for the purpose of terminating the horseradish peroxidase-catalysed oxidation of tetramethylbenzidine, as is frequently used in EIA's, has a large impact on:

- the absorbance maximum of tetramethylbenzidine; 


\section{Vitamin $\mathbb{D}$}

\section{Molecular, Cellular and Clinical Endocrinology}

\section{Proceedings of the Seventh Workshop on Vitamin D}

Rancho Mirage, California, U.S.A. April 1988

Editors $\quad$ A. W. Norman $\cdot$ K. Schaefer $\cdot$ H.-G. Grigoleit $\cdot$ D. v. Herrath

$1988.17 \mathrm{~cm}$ x $24 \mathrm{~cm}$. XL, 1072 pages. Numerous illustrations

Hardcover. DM 390,- ISBN 3110114771

The quality of the science presented at the Seventh Workshop on Vitamin D was outstanding. Major developments were made in understanding of Vitamin D on many research frontiers, including those of the chemists, biochemists, physiologists as well as clinicians who attended the meeting and who are actively conducting research in various aspects of the Vitamin D endocrine system.

\section{From the Contents}

Chemistry of Vitamin D Seco-Steroids - Vitamin D Metabolism and Catabolism . Biochemistry and Regulation of Hydroxylases - Receptors for $1,25(\mathrm{OH})_{2} \mathrm{D}_{3}$ (Biochemistry and Molecular Biology) - Cell Differentiation/Hematopoiesis/Immunology $\cdot$ Gene Regulation by $1,25(\mathrm{OH})_{2} \mathrm{D}_{3} \cdot$ Biological Actions of Vitamin D Metabolites Calbindins (Biochemistry, Molecular Biology, Biological Actions) - Author Index $\cdot$ Key Word Index $\cdot$ Cell Line Index

\section{Also available:}

\section{Vitamin D}

Uremic Bone Disease: 1974. XXIV, 779 pages. DM 205,-

Basic Research: 1979. XXVIII, 1318 pages. DM 220,-

Calcium Metabolism: 1982. XXVIII, 1286 pages. DM 285,-

Chemical, Biochemical and Clinical Update: 1985. XXXVIII, 1249 pages. DM 340;- 
F. Salvatore, A. Roda, L. Sacchetti (Eds.)

\section{Clinical Biochemistry in Hepatobiliary Diseases}

Proceedings of the International Satellite Symposium, Bologna, Italy, 1988

With contributions by numerous experts

1989. DX, 196 pp. 72 figs. 23 tabs. (Progress in Clinical Biochemistry and Medicine, Volume 8). Hardcover DM 142,- ISBN 3-540-50705-1

Contents: I. W. Percy Robb: The Clinical Biochemistry of Hepatobiliary Diseases. - L. Sacchetti, G. Castaldo, F. Salvatore: The Serum Gamma-glutamyltransferase Isoenzyme System and its Diagnostic Role in Hepatobiliary Disease. - D. W. Moss: Alkaline Phosphatase in Hepatobiliary Disease. J. Griffiths: Enzymatic Profiles of Hepatic Disease Investigated by Alkaline Phosphatase Isoenzymes ' and Isoforms. - Y.Artur, G. Siest, G.J.Sanderink, M. Wellman, M.M. Galteau, F. Schiele: Reference Values and Drug Effects on Hepatic Enzymes. S. B. Rosalki: Plasma Amylase in Pancreatic and Hepatobiliary Disease. - N. Blanckaert, J. Feveny, F. Vanstapel, M. Muraca: Clinical Significance of Recent Developments in Serum Bilirubins. A. Roda, D. Festi, C. Armanino, R. Rizzoli, P. Simoni, A.Minutello, E. Roda: Methodological and Clinical Aspects of Bile Acid Analysis in Biological Fluids. $M$. Werner: Strategies to Integrate Laboratory Information into the Clinical Diagnosis of Hepatic and Acute Pancreatic Disease.

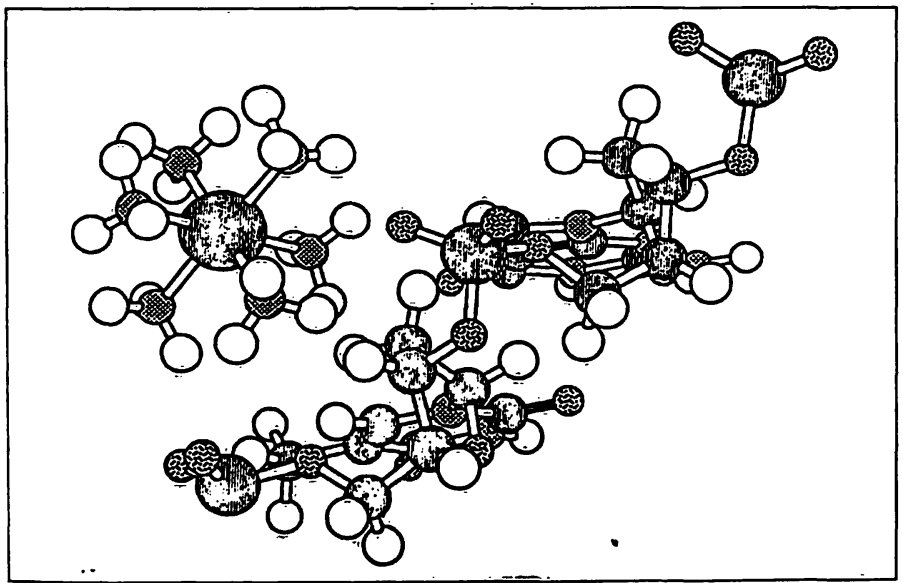

\section{Ruthenium and Other Non-Platinum Retal Complexes} in Cancer Chemotherapy

With contributions by numerous experts 1989. IX, 226 pp. 99 figs. 47 tabs. (Progress in Clinical Biochemistry and Medicine, Volume 10). Hardcover DM 138,- ISBN 3-540-51146-6

Contents: N.P.Johnson, J.-L. Butour, G. Villani, F.L.Wimmer, M. Defais, V.Pierson, V.Brabec: Metal Antitumor Compounds: The Mechanism of Action of Platinum Complexes. - M.J. Clarke: Ruthenium Chemistry Pertaining to the Design of Anticancer Agents. - B. K. Keppler, M. Henn, U.M.Juhl, M.R. Berger, R. Niebl, F.E. Wagner: New Ruthenium Complexes for the Treatment of Cancer. - G.Mestroni, E. Alessio, Trieste, M. Calligaris, W.M.Attia, F. Quadrifoglio, S. Cauci, G.Sava, S. Zorzet, S. Pacor, C.Monti-Bragadin, M. Tamaro, L. Dolzani: Chemical, Biological and Antitumor Properties of Ruthenium (II) Complexes with Dimethylsulfoxide. - N. Farrell: Metal Complexes as Radiosensitizers. - S. C. Srivastava, L.F.Mausner, M.J. Clarke: Radioruthenium-Labeled Compounds for Diagnostic Tumor Imaging. - P. Köpf-Maier: The Antitumor Activity of Transition and Main-Group Metal Cyclopentadienyl Complexes. - E. V.Scott, G.Zon, L. G. Marzilli: NMR Relaxation Footprinting: The $\left[\mathrm{Cr}\left(\mathrm{NH}_{3}\right)_{6}\right]^{3+}$ Cation as a Probe for Drug Binding Sites on Oligonucleotides. - J.E.Schurig, H. A. Meinema, K. Timmer, B. H.Long, A.M. Casazza: Antitumor Activity of Bis [Bis(Diphenylphosphino) Alkane and Alkene] Group VIII Metal Complexes. - M.E. Heim, H. Flechtner, B. K. Keppler: Clinical Studies with Budotitane - A New NonPlatinum Metal Complex for Cancer Therapy.

Distribution rights for the socialist countries: Akademie Verlag, Berlin (GDR)

Springer-Verlag Berlin Heidelberg New York London Paris Tokyo Hong Kong

Heidelberger Platz 3, D-1000 Berlin 33 - 175 Fifth Ave., New.York, NY 10010, USA - 8 Alexandra Rd., London SW19 7JZ, England · 26, rue des Carmes, F-75005 Paris - 37-3, Hongo 3-chome, Bunkyo-ku, Tokyo 113, Japan - Citicorp Centre, Room 1603, 18 Whitfield Road, Causeway Bay, Hong Kong 
- the equilibrium between the charge-transfer complex and tetramethylbenzidine/diimine, which is quantitatively shifted towards the tetramethylbenzidine/diimine side;

- the molar lineic absorbance of the diimine, which is very $\mathrm{pH}$-sensitive; it changes by a factor of 1.4 or 1.1 (this study) or 1.3 (2) when the $\mathrm{pH}$ is decreased from $5.5,4.0$ or 5.0 to (less than) unity, respectively.

Depending on the reaction conditions as well as the reaction coordinate, a combination of the latter two effects causes a substantial increase in the absorbance at $450 \mathrm{~nm}$.

\section{References}

1. Bos, E., Doelen, A. van der, Rooy, A. van \& Schuurs, A. (1981) J. Immunoassay 2, 187-204.

2. Josephy, P., Eling, Th. \& Mason, R. (1982) J. Biol. Chem. $257,3669-3675$.

3. Gallati, H. \& Pracht, I. (1985) J. Clin. Chem. Clin. Biochem. $23,453-460$.

Dr. R. W. Bally

Organon Int. B. V. DRL-D/RE2201

Postbus 20

NL-5340BH Oss

Dr. T. C. J. Gribnau

Organon Int. B. V. DRL-D/RE 2140

Postbus 20

NL-5340BH Oss 